A review of the education system in Norway

\section{primary school}

In Norway today physics is an integral part of the science taught in primary school, but until 1997 physics was hardly taught at this level. Most Norwegian primary school teachers have no science training themselves. The few who have a science education normally have some knowledge of biology, possibly some chemistry, but seldom physics. Also, Norwegian textbooks for primary schools are of highly variable quality in terms of their physics chapters.

From the academic year 97 and 98 on, Norway has new curricula for all levels in compulsory school, following a major national reform. This reform is important for the position of science teaching in primary school. Since the reform, physics and the other science subjects have a far better position. New textbooks have been published for all grades which meet approved levels of technical and pedagogic quality, and a training programme for teachers has been established.

The first science textbooks for teaching the new curriculum have already reached the market. The quality is somewhat variable, but several of them have received very good reviews from the Norwegian physics education establishment.

\section{lower secondary school}

In lower secondary school physics is a part of the science curriculum, but the quality of the physics teaching is much better than it has been in primary school. The textbooks are of better quality than in primary school, but are often too advanced for the pupils who have not previously learned any physics. Teachers in lower secondary school have a better training in science, but again, there is a problem that many have a science training that consists mainly of biology. Approximately three out of every four science teachers in lower secondary school have no training in physics.

Physics teaching in lower secondary school is characterised by the teacher often slavishly following the chosen textbook. Norwegian schools, in general, have very little physics equipment, and as a consequence lessons lack demonstrations and laboratory work.

According to the new curricula, a considerable part of the tuition, in every subject, should be project oriented and integrated with other subjects. This could be an advantage for physics as the subject can be integrated into projects dealing with environmental problems, technology, energy supply, our picture of the universe, etc. On the other hand physics can easily disappear in project work, particularly if the teacher does not have proper physics training and a keen interest in the subject.

\section{physics in teacher training}

Perhaps the most important cause of physics' weak position in compulsory school is our teacher training which barely supplies the student teacher with any training in physics. Nevertheless, any teacher with an exam from a college of education is formally qualified to teach any subject from 1st to 1oth grade (6 to
15 years) including the physics part of science. In other words, Norwegian compulsory schools have no requirements for specific subject teachers.

Until 1992 mathematics and science held very modest positions in teacher training. Mathematics was not a compulsory subject (amazingly) and science training consisted mainly of biology. Most colleges of education did not even employ physicists (or chemists) in their science departments. After 1992 the situation improved. Mathematics is now compulsory for student teachers, and fragments of physics have entered the science curriculum.

Following the strong bid for science in the new curricula for compulsory schools, a heavier emphasis on science is expected in teacher training. To remedy our teachers' lack of competences in science, the government has already granted substantial sums for upgrading courses.

In upper secondary school the situation is quite different: all teachers in physics have at least one year of university training in physics. Forty per cent of Norwegian physics teachers at this level hold a master's degree in physics.

\section{upper secondary school}

In the first year of upper secondary school (16 years) the students read a compulsory integrated science course. The academic track (see below) has five lessons per week. In some vocational tracks there are two lessons per week. The course is normally taught by one teacher, and the allocation between subjects for the five-lesson course is $2 / 5$ chemistry, $2 / 5$ biology and $1 / 5$ physics. Most integrated science teachers are either biologists or chemists. This means that physics occupies the weakest position of the three sciences.

Compulsory school in Norway starts at the age of 6 and finishes at the age of 15. All pupils in the compulsory school system, throughout Norway, are taught the same subjects for all ten years. The only exception is foreign language teaching (all must learn English for 10 years, but have the option of choosing two years of German or French). $98.5 \%$ of all children in Norway attend state schools.

After compulsory school every pupil has the right to be accepted into an upper secondary school for 3 years (16 to 19 years). In 1996 more than $90 \%$ continued into upper secondary school.

At upper secondary school, the pupils may choose between a general academic education, in preparation for entry to a university, or a more vocational education. In recent years $56 \%$ have chosen the former.

Assessment of pupils in Norway does not take place until they are 13 years old. At the end of the 10 th grade ( 15 years) pupils receive an average assessment mark in each subject. One important feature of the assessment, which we believe is unique to Norway, is that pupils receive a national examination in just one of their written subjects. The precise subject to be examined is determined by drawing lots. 


\section{the aim of school physics}

The aims of school physics courses are extensive. On the one hand school physics should be a 'hard' science subject, where the ability to create precise mathematical formulations of physical problems is important. On the other hand it should be a subject with a qualitative character which can give a foundation to scientific reasoning and opinions, and participation in society. It is easy to see, in fact, that we need to include both of these aims.

It could be argued that there are two divergent ideas on what is important in a modern general education in physics. One idea puts emphasis on physics as a general subject, which imparts knowledge of great social and cultural importance. This view implies emphasis on compound and complex topics such as energy problems, radiation and health, and cosmology. Within this perspective physics, to a large extent, becomes a descriptive subject.

The second idea is that school physics shall give an introduction to physics as a special subject and its methods. By this assumption, it is natural to emphasise the basic parts of physics such as mechanics, thermophysics, electromagnetism and the basic experimental nature of physics. This is important for those who want to include physics in their education. It is, however, also important as a part of general education.

Fundamental concepts such as acceleration, force, fields etc, are demanding. When these concepts are introduced to students at school it is not sufficient to use only simplified mathematical formulas. Few students get a deep understanding of Newton's second law by calculating one unknown quantity from two known ones. A qualitative approach to problems, without the need for calculations, must go together with quantitative problems to form a foundation for the concepts of physics.

It is natural to point out the significance of gaining a good scientific knowledge so that one can understand and participate in political and social tasks. This is linked to democratic participation and responsibility. It also means that society needs people who are educated in physics. A society such as Norway is strongly dependent on a high degree of competence within technology and science. Therefore an important task for schools is to give people the opportunity to learn and gain competence in science which is essential for society. Such a perspective need not lead to an antagonism between a general aspect (public understanding of science) and a more academic perspective. Perhaps on the contrary, a subject which appeals to more students, so that more students choose physics, can to some extent raise the general public's competence in science. This in turn may lead to more students being motivated to continue their education in science.

The authors are Carl Angel of the University of Oslo, and Arne Auen Grimnes of the Norwegian Agricultural University. In 1996 both authors were among the founding members of the Norwegian Physics Teacher's Association, the largest section of the Norwegian Physical Society. university level

The physics teaching at Norwegian universities is comparable with that of any English-speaking country, according to Finn Ingebretsen, because they use exactly the same textbooks. English is compulsory in school from an early age, and by the time a student reaches undergraduate level, "textbooks are almost exclusively in English".

Professor Ingebretsen is a nuclear structure experimentalist, and like all of his colleagues in the physics department at the University of Oslo, tries to balances his research time so that he spends exactly half his time at work teaching.

His students tend to get jobs in Norway, rather than move abroad. There is a high demand for physics students, but too few students choosing physics (of course). One reason is perhaps the lack of science awareness in Norway. Last summer, "I was in London at Westminster Abbey and I saw a tombstone on the floor with Paul Dirac's name on it. That would never happen in Norway. We haven't had a Dirac, but you have to be an author or a composer, or a painter maybe," he says.

An exception is the 200 krone banknote, which features Kristian Birkeland."He was a genius. He was a professor in the early half of this century, and his basic research was in Aurora, or Northern Lights, research. He had 52 patents, with which he financed his research," Ingebretsen says. "When that banknote was introduced representatives of our institute were invited to the Norwegian bank. Our institute orchestra played. It was a big event."

Norway is a small country with a colonial history. "Norway was a colony until 1905. It was a part of Denmark for four hundred years until 1814, and then a part of Sweden until 1905. During the Danish period it was really a province."

Today the country is fairly rich: "Lumber export and fish, and now oil, are the basis of the nation's economy," says Ingebretsen. Unfortunately this has not, Ingebretsen feels, created the need for many more scientists, as it might have done in another country.

Norwegians go to university at the age of 18 or 19 . There is compulsory military service for the boys, which lasts less than one year, and can be postponed until after studies. The first degree, Cand Mag for short, lasts three-and-a-half years. Students study two or three subjects, not just one, and they must accomplish at least 31 per cent of their course in physics in order to "major" in physics. Nearly eight per cent of a degree is compulsory philosophy.

A masters degree, called Cand Scient for short, is supposed to last one-and-a-half years, but is usually closer to 2 years. It consists of half-a-year of studies, and then a thesis. Students fund themselves with a bank loan.

Funding for a doctors degree, which typically lasts a further three or four years, is taken care of by a scholarship, either from the university itself, the national research council, or from industry. 